\section{Globalisation and mental disorders}

\author{
Overview with relation to depression
}

DINESH BHUGRA and ANASTASIA MASTROGIANNI

\begin{abstract}
Background Globalisation is the process by which traditional boundaries of cultures are changing. Industrialisation, urbanisation and influence of the media are influencing idioms of distress across cultures.
\end{abstract}

Aims To discuss the role of globalisation, using the epidemiology, diagnosis, clinical presentation and treatment of depression across various cultures as an example.

Method Recent studies focusing on transcultural aspects of depression were reviewed and summarised.

Results Cultural, social and religious mores account for variations in the presentation of depression across cultures. Somatic symptoms are common presenting features throughout the world and may serve as cultural idioms of distress, but psychological symptoms can usually be found when probed. Feelings of guilt and suicide rates vary across cultures and depression may be underdiagnosed.

Conclusions Training packages could enhance clinicians' cultural competency in multicultural settings. However, globalisation is likely to influence idioms of distress and pathways to care in ways that are difficult to predict.

Declaration of interest None. D.B. has presented papers at meetings that have received educational grants from Eli Lilly, Lilly Suisse, Sanofi-Synthelabo, Janssen-Cilag and AstraZeneca.The current paper has not been a part of any such lecture and no fee has been accepted in the context of this paper.
We have entered the brave new world of globalisation. This term has been overused and even misused (Jones, 1995). Broadly, globalisation may be defined as a process in which the traditional boundaries separating individuals and societies gradually and increasingly recede. This process is changing the nature of human interaction in many spheres: economic, political, social, cultural, environmental and technological. It is changing the way we perceive time and space, and the way we think about the world and ourselves (Kunitz, 2000; Lee, 2000).

Different philosophical and ideological approaches have led to polarised views about the impact of globalisation on individuals and society. However, the process clearly has both negative and positive results and it is likely to create both losers and winners. Societies alter rapidly through urbanisation, acculturation, modernisation, and social and cultural change. The quality of life in many countries is affected by economic disintegration, unequal distribution of collective wealth, social disruption, political repression, migration and even war. Millions of people still lack food, water, education and basic health care. Global economic forces have weakened poor countries and communities on one hand and reinforced the economic status of wealthy countries on the other. However, the greatest inequalities are often to be found within the borders of nation-states, rather than between underdeveloped and developed countries. The complex links between globalisation, health, and social and mental well-being are only now beginning to be explored, and researchers emphasise the need for a clearly defined research and policy agenda to respond to the challenges posed (Lee, 2000).

\section{GLOBALISATION AND CULTURE}

As a concept, globalisation may have replaced universalisation. Psychiatrists generally adopt a universalist view in the sense that underlying human physiological, and to some extent psychological, responses are universal, whereas anthropologists argue for a relativist position. Relativists fear that economic liberalisation and globalisation will turn individuals and their spaces into more homogeneous entities. A common view of globalisation is that it will lead to things getting out of hand. Power appears to be shifting from the state to multinational corporations, some of which have a market value exceeding the gross domestic product of many countries. The role of the state and bureaucracy adds another variable to how globalisation will influence countries and their inhabitants.

As a result of the unqualified and unstoppable spread of free trade rules - and above all the free movement of capital the economy is progressively exempt from political control. Thus, the economic impotence of the state will influence how individuals see their role, their self-esteem and their value in the larger scheme of things. Bauman (1998) illustrates how the role of the media in the portrayal of poverty, famine and natural disasters in faraway lands makes individuals in developed countries immune to the impact of these tragedies. Globalisation is breaking down natural boundaries: we can travel from one culture to another through television, the internet, cinema and books. Consumerism associated with this movement raises expectations and aspirations. Economic migrants - if they are well educated - experience no barriers and enjoy a multinational culture in which they can have Chinese food in Paris, French food in India and Indian curry in Hong Kong. Bauman (1998) differentiates between vagabonds and tourists: the former are economic refugees and the latter generate income. Globalisation is turning those who are poor, uneducated and rootless into vagabonds who are allowed neither to stay put nor to search for a better place to be. Cultural hybridisation may be a creative, emancipating experience but cultural disempowerment of the locals seldom is, yet the two processes are difficult to disentangle.

\section{A philosophical issue}

Globalisation may also be seen as a philosophical issue. Changes in identity, both individual and group, and the assimilation of national markets into a single 
sphere may be said to be attributable to globalisation. Globalisation means the import and export of the cultures too and may reduce politics to the administration of sameness. Like globalisation, culture is an abstract concept that also covers a broad territory. It refers to patterns of perceiving and adapting to the world. Culture is reflected in the learned, shared beliefs, values, attitudes and behaviours characteristic of a society or population. Although there is more than one definition of culture, there seems to be an agreement that culture is learned and shared, it is dynamic and ever-changing, and it is the way people structure and adapt to their internal and external environments.

If cultures were once viewed as closed, self-contained systems with strict and resistant boundaries, in the era of globalisation they are described as ever-changing constructs that emerge from interactions between individuals, communities and institutional practices (Kirmayer, 2001). Although there have been concerns that globalisation will eventually lead to the homogenisation of culture and identity, there is evidence that this process is being opposed by the tendency for communities to retain or assert their ethnic identity in its extreme form leading to the rise of neo-nationalist and fundamentalist movements (Bibeau, 1997).

\section{Interconnectedness of cultures}

Inda \& Rosaldo (2002) refer to globalisation as the intensification of global interconnectedness, suggesting a world full of movement and mixture, contact and linkages, and persistent cultural interactions and exchange. The technologies of communication and transport have made capital more and more mobile, and the search to reduce production costs and maximise profits has led multinational corporations to shift production ever further afield. The human cost is not a consideration in capital accounting. However, globalisation can benefit individuals by allowing them to partake in other, immigrant cultures, which may increase their aspirations. With increasingly complex interconnectedness, not only can capital traverse frontiers almost effortlessly, drawing places into dense networks of financial hegemony, but also people (equated with cheap labour) move across national boundaries, turning private territories into public spaces where cultures clash, converge and struggle with each other.

The rapid flow of capital, people, goods, images and ideologies pulls the world together in a tight net which may sometimes strangle the individuals it is meant to liberate. This interconnectedness can be traced back to European colonialism, which began the process of cultural homogenisation across geographical boundaries.

Harvey (1989) conceptualised globalisation principally as a compression of time and space: one can only speculate about the impact of such a compression on an individual's psyche and social functioning. This compression does not occur in a continuous manner but in short, concentrated bursts which may allow the affected culture to bounce back or respond in a more careful manner. Giddens (1990) refers to the 'conditions under which time and space are organised so as to connect presence and absence'. Social encounters may be immediate and face to face, or remote, relying on transport and communication across space and time. Globalisation thus leads to ever greater numbers of people living in circumstances in which disembodied institutions linking local practices with globalised social relations organise major aspects of day-to-day life (Giddens, 1990), producing a dissonance that alienates individuals from both localities and global space.

\section{'Territorial' issues}

Cultures experience both 'territorialisation' and 'de-territorialisation' as a result of globalisation (Inda \& Rosaldo, 2002) the 'de' pulls culture apart from place, and 'territorialisation' is always there to pull it back in one way or another. This discourse understands the increased global movement of cultural goods primarily as a process of cultural imposition and global dominance-largely of European and American sensibilities. This cultural homogenisation and globalisation can be seen as conveyance of cultural styles. Globalisation is defined by Tomlinson (1997) as 'the continuation of a long historical process of western "imperialist" expansions - embracing the colonial expansions of the 16th-19th centuries and representing an historical pattern of global cultural hegemony'. What does this do to individuals in vulnerable cultures? It may make individuals feel alienated if they do not change, making them feel backward and old-fashioned. If they do change, then the change may alienate them from their roots and yet they may still not be acceptable to the new cultural norms. The processes of acculturation, assimilation, deculturation or biculturalism may emerge as a result of globalisation (Bhugra \& Ayonrinde, 2004).

Friedman (1988) argues that in cities that host global economic activities, 'economic space' has ascendancy over 'life space', and that people's survival activities are marginalised by the activities of the rising global business class. Interestingly, such a process also leads to communal space impinging upon individual space. Mahadevia (2002) observed that both objective conditions and subjective forces interact to influence an individual's functioning. Globalisation of cities has been launched through new systems of resource mobilisation and urban governance that rely on privatisation and commercialisation of their infrastructure. Mahadevia (2002) goes on to suggest that cities attempt to improve their economic efficiency by processes of exclusion - exclusion of marginal areas and of segments of the population who cannot afford the costs of living in the rapidly globalising urban space. As a result of economic pressures, more land is allocated to commercial and industrial use, increasing control of the environment and infrastructure by business and reducing the role of the state from a welfare entity to a market-friendly (even market-led) system of governance. This generates high levels of poverty, which in combination with vulnerability to unemployment, altered social support systems and poor housing, cause the poor to end up in distress and at increased risk of psychiatric disorders. Illustrating these pressures on the city of Ahmedabad, Mahadevia (2002) points out that the debt burden on the city has increased eight-fold since economic liberalisation, leading to the city's withdrawal from non-obligatory functions.

\section{Identity, unity and division}

From the perspective of cultural psychiatry, culture influences the sources, the symptoms and the idioms of distress; the individuals' explanatory models, their coping mechanisms and their help-seeking behaviour; as well as the social response to distress and to disability (Kirmayer, 2001).

Ethnic identity has a role in individuals' self-esteem and it affects the social causes 
and courses of psychiatric disorders. The consequences of the new pluralist context of multicultural societies for individuals' psychological well-being are largely unknown. Cultural psychiatrists continue to study identity systems - the ones threatened by the globalisation process - but are becoming more sensitive to multiple belongings, multi-ethnic communities, longdistance networks and flexible identities (Bibeau, 1997).

Globalisation divides as much as it unites, and the causes of division are identical to those promoting global uniformity (Bauman, 1998). The emerging dimensions of business, finance, trade and information flow are accompanied by a space-fixing process. Bauman (1998) suggests that between these two effects lies the sharp differentiation between various segments of the population. Globalisation for some means localisation for others. Being local may be seen as a sign of backwardness, whereas being global may be a sign of modernity. An integral part of the globalising process is progressive spatial segregation, separation and exclusion. This, combined with a sense of alienation, can be seen as a cumulative way of increasing the stress of vulnerable individuals. It is possible that with such processes of globalisation, cultures may be denuded of their psychologically protective effects.

\section{GLOBALISATION AND MENTAL HEALTH}

Despite evidence that all mental disorders are psychobiosocial in origin and that the quality of social environment is related to the risk of mental illness, it is difficult to predict the impact of globalisation on the prevalence and course of psychiatric disorders. What is certain, however, is that mental disorders can no longer be dissociated from the global context that frames our lives. According to Kirmayer \& Minas (2000), globalisation affects psychiatry in three main ways: through its effect on the forms of individual and collective identity, through the impact of economic inequalities on mental health, and through the shaping and dissemination of psychiatric knowledge itself. They identify both the tendency for communities to reassert their distinctive ethnic identity, and the 'creolisation' of identity and of the cultural idioms through which emotional distress is communicated. The key factor in globalisation is urbanisation.

Through mass media and electronic telecommunication, the horizon of loca cultures may greatly expand, reaching many other ethnic cultures around the world (Kirmayer \& Minas, 2000), to the extent that the distant may become more familiar and frequented than the physically close. Kirmayer \& Minas (2000) argue that homogenisation is unlikely because the process of globalisation affects only a minority and is counteracted by the urge to assert one's own ethnic identity. However, the economic pressures of capitalism are likely to lead to an increase in urbanisation with its related rootlessness.

\section{Urbanisation and industrialisation}

Urbanisation is the relative increase of the urban population as a proportion of the total population (Harpham et al, 1988), and it is occurring on a scale never before experienced. Kleinman (1991) observed that urbanisation has led to a massive increase in behavioural disturbance especially associated with breakdown of families, including abandonment of and violence to spouses, children and the elderly - as well as depressive and anxiety disorders (although he cautions that the apparent increase in the latter disorders may be due to more accurate reporting). Harpham (1994) presented a model of the interlinking of urbanisation and mental disorders in which long-term difficulties, increased life events and reduced social support act as mediating factors. Chronic difficulties such as poor, overcrowded physical environments, high levels of violence and accidents, insecure tenure and poor housing have all been shown to be associated with depression.

There have been suggestions that social deviance could be traced to many of the social processes accompanying urbanisation, including competition, class conflict, accommodation and assimilation (Park et al, 1925). Marsella (1995) proposed that urban settings represent a natural laboratory for studying the roots of traditional mental disorders such as depression, schizophrenia and neurosis, and that a conceptual framework which considers the stress associated with problems of housing, work, marriage, child rearing, security and other urban difficulties in simultaneous interaction with the resources available for their resolution or attenuation provides the best understanding of the determinants of psychopathological disorder in urban populations. Other researchers (Desjarlais et al, 1995; Bibeau, 1997) emphasise the link between mental health and poverty, economic disparity and underdevelopment. Urban crowding, poor working conditions or underemployment, chronic hunger, gender discrimination, limited education and human rights violations are all thought to weaken and devastate both individuals and the social supports that could serve as buffers against mental health problems. Moreover, economic factors determine the availability and quality of mental health services.

\section{Therapeutic advances and growing disease burden}

Significant advances have been made in the development of both psychoactive medications and psychosocial therapies, and many psychiatric disorders can now be effectively treated. The globalisation of information technologies enables mental health professionals to exchange knowledge and experience and allows groups of users and caregivers to become better informed and influential. The production and exchange of psychiatric knowledge seems to remain tied to political and economic issues, however, and the prominent role of the pharmaceutical industry in psychiatric research and education may threaten the development of psychosocial interventions (Kirmayer \& Minas, 2000).

Mental illness constitutes a huge burden throughout the world. According to a World Bank study (World Bank, 1993), mental health problems account for $8 \%$ of all lost years of quality life. For adults aged 15-44 years living in 'demographically developing economies', neuropsychiatric diseases are $12 \%$ of the global burden of disease. Most researchers underline the likelihood that the number of persons with major mental illnesses and the societal burden of mental health problems will be increased substantially in the years to come by the impact of globalisation (Desjarlais et al, 1995; Bibeau, 1997).

Globalisation is likely to increase social inequality by exacerbating differences in access to and distribution of resources. Persaud \& Lusane (2000) suggest that technical economic processes are related to both class and racial discrimination. Such social factors are likely to increase the risks of collective violence and civil war; in addition, risks such as those of 
Table I Transcultural variation in the prevalence of depression: results of a World Health Organization study (data from Goldberg \& Lecrubier, 1995)

\begin{tabular}{llc}
\hline Centre & Country & $\begin{array}{c}\text { Current } \\
\text { depression (\%) }\end{array}$ \\
\hline Santiago & Chile & 29.5 \\
Rio de Janeiro & Brazil & 15.8 \\
Paris & France & 13.7 \\
Manchester & UK & 16.9 \\
Groningen & The Netherlands & 15.9 \\
Mainz & Germany & 11.2 \\
Bangalore & India & 9.1 \\
Athens & Greece & 6.4 \\
Berlin & Germany & 6.1 \\
Ankara & Turkey & 11.6 \\
Seattle, WA & USA & 6.3 \\
Verona & Italy & 4.7 \\
Nagasaki & Japan & 2.6 \\
Shanghai & China & 4.0 \\
Ibadan & Nigeria & 4.2 \\
Total & & 10.4 \\
Men & & 6.8 \\
Female & & 12.4 \\
\hline & & \\
\hline
\end{tabular}

terrorist attacks, exposure to dangerous substances and the spread of drug-resistant disease, resulting from increases in international travel and commerce, as pointed out by Howson et al (1998) are likely to have an impact on mental health that should not be underestimated.

\section{GLOBALISATION AND DEPRESSION}

Depression can serve as a paradigm in the discussion of the impact of globalisation in the prevalence of mental disorders, idioms of distress and pathways to care. Depression can occur as a single episode in a lifetime, as one of many episodes, or as a part of an alternation with mania (American Psychiatric Association, 1994). The cultural background is likely to determine whether depression will be experienced and expressed in psychological and emotional terms, or in physical terms (Desjarlais et al, 1995).

Depression is a highly prevalent disorder. Indeed, the experience of dysphoric mood is now considered to be a universal phenomenon, although the clinical features may differ significantly across different cultures. According to the World Development Report 1993, depression ranks fifth among women and seventh among men as a cause of morbidity (World Bank, 1993). The World Health Organization predicted that in the year 2020 depression will be, worldwide, the second most important cause of disability after ischaemic heart disease. More importantly, in developing countries major depression is projected to be the leading cause of disease burden (Murray \& Lopez, 1997). From this perspective, we review recent research into cultural variations in epidemiology, diagnosis, clinical presentation and treatment of depression and into how globalisation will influence idioms of distress, pathways to care and help-seeking.

\section{Epidemiology of depression}

\section{WHO study on psychological problems}

A large study by the World Health Organization (WHO) (Sartorius et al, 1996) investigated common psychological problems in primary care settings in 14 different countries (25916 adults). About a quarter $(24 \%)$ of the primary care attenders worldwide received an ICD-10 psychiatric diagnosis (World Health Organization, 1992): the most common was 'current depressive episode' $(10.4 \%)$. The most frequent comorbid disorders were depression and anxiety. However, marked differences were observed in the prevalence of depression at different centres, even after correction for between-centre differences such as age (Table 1). Different levels of awareness and recognition for cultural reasons (Lecrubier, 2001), popular perceptions of in general health care

the role of the doctor in each country, and different pathways to care and health systems (for example, medical care must be paid for at the Ibadan centre, which had one of the lowest prevalence rates) have been identified as some of the important contributing factors in this variation (Goldberg, 1999).

\section{Cross-National Collaborative Group study}

The Cross-National Collaborative Group (Weissman et al, 1996) carried out epidemiological community studies in ten countries. The methods of collecting the data and the fact that they were collected in the late 1980s and early 1990s could explain why the rates are generally lower than those recorded in later years (Lepine, 2001). Again, the lifetime prevalence of depression varied widely, with extremes of $1.5 \%$ in Taiwan and $19 \%$ in Beirut (Table 2). Women had a higher rate than men in all the countries, and the mean age at onset was concentrated around the late twenties in most countries. At all sites, increased risk of comorbid alcohol misuse or dependence, panic disorder and obsessive-compulsive disorder was recorded for patients with depression. As in the WHO study, the variability in rates is not easy to explain. Korea had rates of depression twice as high as those in Taiwan, although they are both Asian industrialised nations. Paris had a rate approaching that of Beirut, although the latter city had been ravaged by war for 15 years. Different risk factor profiles across countries, social stigma, cultural reluctance to endorse mental symptoms, and limitations of the study itself may account, according to the researchers, for some of the differences (Weissman et al, 1996).

Table 2 Transcultural variation in the prevalence of depression: results from the Cross-National Collaborative Group (data from Weissman et al, 1996)

\begin{tabular}{lccc}
\hline & $\begin{array}{c}\text { Lifetime rate } \\
\%(s . e .)\end{array}$ & $\begin{array}{c}\text { Female:male ratio } \\
\text { Mean (s.e.) }\end{array}$ & $\begin{array}{c}\text { Age at onset (years) } \\
\text { Mean (s.e.) }\end{array}$ \\
\hline USA & $5.2(0.24)$ & $2.6(0.11)$ & $25.6(0.30)$ \\
Canada (Edmonton) & $9.6(0.60)$ & $1.9(0.13)$ & $24.8(0.52)$ \\
Puerto Rico & $4.3(0.59)$ & $1.8(0.29)$ & $29.5(1.19)$ \\
France (Paris) & $16.4(1.16)$ & $2.1(0.16)$ & $29.2(0.52)$ \\
West Germany & $9.2(1.50)$ & $3.1(0.39)$ & $29.7(1.18)$ \\
Italy (Florence) & $12.4(1.33)$ & $3.0(0.26)$ & $34.8(1.12)$ \\
Lebanon (Beirut) & $19.0(1.76)$ & $1.6(0.19)$ & $25.2(1.00)$ \\
Taiwan & $1.5(0.12)$ & $1.6(0.17)$ & $29.3(0.88)$ \\
Korea & $2.9(0.24)$ & $2.0(0.18)$ & $29.3(0.88)$ \\
New Zealand (Christchurch) & $11.6(0.96)$ & $2.1(0.18)$ & $27.3(0.58)$ \\
\hline
\end{tabular}


Bland (1997) reviewed a number of community surveys on major depression, and found that rates of depression differed significantly between sites. Almost without exception, higher rates were documented in women than in men. Regarding age at onset, no significant difference was found between men and women, and little difference between sites. There is growing evidence however that rates of depression are increasing, particularly in cohorts born after the Second World War, with an earlier age of onset and some narrowing of the gender differences.

\section{Studies of ethnic minorities in the USA}

Studies from the USA generally agree that rates of depression among African Americans and White Americans are comparable when demographic, sociocultural and socio-economic factors are controlled (Comstock \& Helsing, 1976; Neff \& Husaini, 1980; Roberts et al, 1981; Somervell et al, 1989; Kessler et al, 1994; Diala et al, 2001). However, Puerto Ricans have been found to have higher depression rates than Whites (Oquendo et al, 2001), whereas Asian Americans, despite having comparable levels of depressive symptoms, have a lower prevalence of depression (JacksonTriche et al, 2000). Cultural differences among the minority groups, different ethnicity, social class and even different reasons for migration should not be underestimated, and may contribute to this variation.

\section{Studies of ethnic minorities in the UK}

Depression among minority groups in the UK has not been studied as thoroughly as psychosis and the results are inconsistent. Several authors have reported higher community prevalence rates of depression in some minority groups than in the dominant population (Meltzer et al, 1995; Commander, 1997b; Nazroo, 1997; Lloyd, 1998). Shaw et al (1999), comparing African-Caribbean and White European groups in Manchester, found that the prevalence of depression was higher in the former, although this was significant only for women. Bhui et al (2001), in a twophase survey in London with recruited Punjabi and English general practice attenders, reported that the Punjabis were not rated as having more depression than the English participants, but they did have more depressive ideas. Different sites, different minority populations and methodological issues might account for the inconsistency of the results.

\section{Community surveys}

In India, in a survey of slums in Greater Mumbai, Blue et al (1995) found that $17.6 \%$ of women had mental illness. In the two slum settlements furthest away from the facilities (of health centre, voluntary organisation and marketplace) the proportion of probable cases rose to $25-28 \%$. In this sample, more than two-fifths of women complained of feeling tired all the time and over a third reported feeling nervous, tense, worried and easily tired. The middle migrants (those with an urban stay of 6-10 years) reported the least illness. In Brazil, the same group found that almost half $(46 \%)$ of women in a slum area had psychiatric disorders, and that being older, illiterate and a displaced worker and having lower income were more likely to be associated with psychiatric disorder. In Chile, a similar proportion $(44.6 \%)$ of women in Santiago were reported to have a psychiatric disorder (Blue et al, 1995). These authors report that the uncertainty in these women's lives, accompanied by poverty and domestic violence, make it 'normal' that they should feel depressed, anguished and unable to cope, and that telling them that they are psychiatrically ill would only add to their emotional burden.

\section{Diagnosis \\ Methodological issues}

Ballenger et al (2001) suggest that variations across cultures do not necessarily reflect social or medical reality, but to an unknown extent may be consequences of methodological issues, such as differences in population sampling and methods of clinical assessment, differences in classification, and lack of culturally appropriate instruments (or problems related to their translation and validation). There is a debate about the two epistemological approaches within cross-cultural psychiatry: universalism and relativism. This debate reflects on the use of either etic or emic instruments for the recognition and evaluation of mental health disorders, and it is discussed elsewhere (Kleinman, 1988; Fabrega, 1989; Thakker \& Ward, 1998). In order to overcome the limitations of both these approaches, researchers now attempt to combine quantitative research with a more flexible approach using the local narratives and explanatory models of mental disorders (Weiss et al, 1992; Lloyd et al, 1996). Bhui suggests that epidemiologists need to learn more about qualitative data analysis, its use with quantitative data and the limitations of each approach (Bhui, 2001; Bhui \& Bhugra 2001). Moreover, most authors agree that the 'Western' classifications of depression proposed by both ICD-10 and DSM-IV (American Psychiatric Association, 1994) are not entirely satisfactory (Maser et al, 1991; Manson, 1995; Bhugra, 1996).

Although DSM-IV suggests a cultural formulation as a supplement to the multiaxial assessment (American Psychiatric Association, 1994), it is argued that it still represents Western concepts of illness and might not be easily applicable to other cultures (Weiss et al, 1995; Ballenger et al, 2001; Kirmayer, 2001). However, because diagnostic systems are necessary for comparisons between different cultures, defining concepts of depression in accord with both psychiatric and indigenous belief systems and taking into account social contexts and cultural forces that give meaning to everyday life should all be incorporated into psychiatric evaluation and practice (Bhui, 1999).

\section{Diagnosis in primary care}

There is evidence that depression is underrecognised and undertreated throughout the world, especially in primary care (Ballenger et al, 2001; Lecrubier, 2001). In the WHO study (Sartorius et al, 1996), marked variations between centres were

Table 3 Transcultural variation in recognition by primary care physicians among patients with an ICD-I0 diagnosis of current depression (data from Lecrubier, 200I)

\begin{tabular}{lc}
\hline Centre & $\begin{array}{c}\text { Patients with depression } \\
\text { recognised by primary care } \\
\text { physician (\%) }\end{array}$ \\
\hline Ankara & 28.4 \\
Bangalore & 45.7 \\
lbadan & 26.6 \\
Manchester & 69.6 \\
Nagasaki & 19.3 \\
Paris & 61.5 \\
Rio de Janeiro & 43.9 \\
Seattle & 56.7 \\
Total & 53.9 \\
\hline
\end{tabular}


recorded in the numbers of depressed patients who were also diagnosed by the primary care physician (Table 3). Overall, the clinicians detected only half of the cases of depression. There was a linear relationship between 12-item General Health Questionnaire score and percentage of recognition.

Primary care research in the UK shows that although people of south Asian origin visit their general practitioner more frequently than do Whites, they are less likely to have their psychological difficulties (especially depression) identified (Gillam et al, 1980; Commander et al, 1997a; Bhui et al, 2001). This is often attributed to the fact that south Asian patients may appear with mainly somatic complaints and are less willing to express depressive ideas. Jacob et al (1998) reported that in their sample of Indian women in a general practice in London, the doctors' recognition rate had a sensitivity of $17 \%$ and a specificity of $91 \%$. Individuals who did not disclose all their symptoms were less likely to be detected. Studies from the USA have also shown that primary care physicians are less likely to detect depression among African American and Hispanic patients than among Whites, especially if doctor and patient are of a different race (Leo et al, 1998; Borowsky et al, 2000). Comino et al (2001) reported that in Australia, Asian patients have lower rate of general practitioner diagnosis compared with Australian patients, although they record a similar rate of self-reported symptoms. They also tend to be more dissatisfied with services and, along with other non-Englishspeaking patients, would like more time to discuss their problems with their general practitioner.

Authors have offered several explanations for this almost universal phenomenon of underdetection of depression in primary care (Table 4). Multi-factorial educational approaches for both the public and general practitioners, such as the Defeat Depression campaign in the UK, and strategies for the detection and management of depression at a local and national level are proposed as measures that could alter practice (Bhugra, 1996; Rait et al, 1999).

\section{Clinical features}

The experience of depression is recognisable in any culture in which it has been sought, although its clinical presentation may vary widely. Even core symptoms such as depressed mood or loss of interest may not be prominent in many cultures. The WHO Collaborative Study on the Assessment of Depressive Disorders (Sartorius et al, 1983), conducted in Basle, Montreal, Nagasaki, Teheran and Tokyo, reported that the most common symptoms (75\% of cases) across sites were sadness, joylessness, anxiety, tension, lack of energy, loss of interest, loss of ability to concentrate, and ideas of insufficiency, inadequacy and worthlessness. Feelings of guilt and self-reproach were more prominent in Basle and Montreal. Suicidal ideation ranged from $70 \%$ in Montreal and Nagasaki to $41 \%$ in Tokyo. Somatic symptoms were most common in Teheran and least frequent in Montreal. The variations in symptoms can be seen as culturally influenced.

\section{Depression and somatisation}

Earlier theories suggested that somatisation was the cultural equivalent of depression, typically occurring in non-Western cultures. There is now growing evidence that somatic symptoms are common presenting features of depression throughout the world (Bhatt et al, 1989; Ebert \& Martus, 1994; Katon \& Walker, 1998; Simon et al,
1999). The terms 'anxiety' and 'depression' as used in English both have essentially somatic roots. Colloquial British expressions such as 'I feel gutted' also describe feelings of loss and depression in somatic metaphorical terms.

Simon et al (1999), using data from the WHO Study on Psychological Problems in General Health Care, examined the relationship between somatic symptoms and depression. The proportion of patients with depression who reported only somatic symptoms ranged from $45 \%$ in Paris to 95\% in Ankara (overall prevalence 69\%). However, when somatisation was defined as 'medically unexplained somatic symptoms' or 'denial of psychological distress', no significant variation between centres was found. The authors concluded that the frequency of somatic symptoms depends on how somatisation is defined.

It has been suggested that somatisation is a concept that reflects the dualism inherent in Western biomedical practice, whereas in most of the great traditions of medicine (such as Chinese or ayurvedic medicine) a sharp distinction between the 'mental' and the 'physical' does not occur (Kirmayer \& Young, 1998). People from traditional cultures may not distinguish between the emotions of anxiety, irritability and depression because they tend to express distress in somatic terms (Leff, 1977) or they may organise their concepts of dysphoria in ways different from Western ones. For example, Chinese people have lower rates of depression and tend to deny depression or express it somatically (Sartorius et al, 1996; Zhang et al, 1998). Parker et al (2001), in a review of the relevant literature, attributed this to a set of interconnecting influences. By the 1980 s, four-fifths of psychiatric outpatients in China were diagnosed as 'neurasthenic' and half sought treatment for

Table 4 Underdetection of depression in primary care, in transcultural settings

Explanation

Different explanatory models between patient and clinician

Unwillingness to disclose all symptoms to the doctor; focusing on somatic symptoms

Variation of clinical features across cultures; use of somatic metaphors Linguistic, cultural and racial barriers between doctor and patient Insufficient probing by the clinician

Physician's familiarity with depression and attitude towards depression Patient's age; coexistence of a somatic diagnosis
Study

Jacob et al (1998), Ballenger et al (200 I), Bhugra (200 I), Bhui et al (200 I)

Weiss et al (1995), Jacob et al (1998), Bhui et al (200 I), Lecrubier (200 I)

Bebbington (1993), Manson (1995), Bhugra et al (1997a), Patel (2000)

Brewin (1980), Leo et al (1998)

Weiss et al (1995), Ballenger et al (200 I), Comino et al (200 I)

Leo et al (1998), Borowsky et al (2000)

Lecrubier (1998) 
self-diagnosed neurasthenia. The concept of neurasthenia is described by the Chinese as shenjing shuairuo and it includes somatic, cognitive and emotional symptoms in addition to any depressive symptoms. This concept fits well with the traditional epistemology of disease causation on the basis of disharmony of vital organs and imbalance of qi. Pang (1998), exploring ways in which elderly Korean immigrants in the USA express depression, concluded that they also express emotions symbolically or physically. These physical terms are neither bodily nor emotional, but somewhere between. Dysphoria was expressed in holistic symptoms ('melancholy has been absorbed into my body'). The speakers were not somatising, just speaking metaphorically in expressing emotion. This is in accordance with Korean traditional medicine, which allots symbolic functions to each body organ: the lungs are related to worry, sorrow and low spirit; the liver to anger; the kidneys to fear.

Bhui (1999), reviewing the literature on common mental disorders among Indian and Pakistani people, refers to the 'black box of somatisation'. He reported that Punjabi patients visiting their general practitioner more often had depressive ideas, but were no more likely to have somatic symptoms than English patients (Bhui, 2001). Pain was the most common physical symptom. This, in an Asian culture, could reflect 'suffering' and dependency needs, while disguising the affective aspects of common mental disorder. Punjabi women participating in a focus group in London (Bhugra et al, 1997b) recognised the English word 'depression', but the older ones used terms such as 'weight on my heart/ mind', or 'pressure on the mind'. Symptoms of 'gas' and 'feelings of heat' were identified, which is in accordance with traditional and ayurvedic models of hot and cold. All the participants were aware of the condition and of the link between bodily and emotional states.

Studies from the Indian subcontinent report inconsistent results regarding the frequency of different symptoms of depression as well as of somatic symptoms (Bhugra, 1996, 2001). Different areas of India have different languages, religions and rituals. These, along with methodological issues, may account for some of the variations in research findings. Women from north India are more likely to present with 'sinking heart', a symptom also noted among Punjabis in the UK (Bhugra et al, 1997a).
Complaints of feelings of heat are once again identified, and this model may have implications for treatment and further investigation. Weiss et al (1995) reported that people with depression attending an outpatient clinic in Bangalore typically presented with somatic symptoms initially. There was a repetitive pattern of reporting somatic symptoms spontaneously, but identifying depressive symptoms only when probed.

Hamdi et al (1997), exploring the detection of depression in the United Arab Emirates, found that Arab patients use a variety of somatic metaphors to describe depression. Sulaiman et al (2001a), conducting focus groups to identify terms and descriptions used for depression in Dubai, report that natives of Dubai, like other Arab populations, are more likely than Western people to associate depression with aches, pains and weakness. The term 'depression' itself is absent from the languages of many cultures (Manson, 1995); it is used rarely in others (Hamdi et al, 1997), or it is construed differently (Abusah, 1993; Lee, 1998). It is likely that the terms will change as a result of global influence.

\section{'Somatisation' or somatic metaphors?}

Researchers seem to agree that each culture has its own emotional lexicon that encodes socially and morally significant values and its own idioms of distress - cultural ways of talking about distress (Table 5).

Table 5 Somatic idioms of distress

\begin{tabular}{|c|c|c|}
\hline Country or culture & Study & Somatic idiom \\
\hline India & Bhugra et al $(1997 a, b)$ & $\begin{array}{l}\text { 'Sinking heart' } \\
\text { 'Feeling hot' } \\
\text { 'Gas' }\end{array}$ \\
\hline Nigeria & Ebigbo (1982) & $\begin{array}{l}\text { 'Heat in the head' } \\
\text { 'Biting sensation all over the body' } \\
\text { 'Heaviness sensation in the head' }\end{array}$ \\
\hline Mexican Americans & Jenkins (1988) & $\begin{array}{l}\text { 'Nervios' - 'brain ache', 'brain exploding' } \\
\text { or 'uncontrollable' }\end{array}$ \\
\hline Chinese & Parker et al (200 I) & 'Shenjing shuairuo' - neurasthenia \\
\hline Dubai & Sulaiman et al (200 la) & $\begin{array}{l}\text { 'Sadri dayeq alayya' - 'My chest feels tight' } \\
\text { 'Tabana' - 'I am tired, fatigued' } \\
\text { 'Jesmi metkasser' - 'broken body' }\end{array}$ \\
\hline United Arab Emirates & Hamdi et al (1997) & $\begin{array}{l}\text { 'The heart is poisoning me' } \\
\text { 'As if there is hot water over my back' } \\
\text { 'Something is blocking my throat' }\end{array}$ \\
\hline
\end{tabular}

Although these idioms may not have been anticipated by the Western diagnostic systems, they may represent the physiological equivalent of the somatic symptoms specified by the ICD or the DSM (Manson, 1995). In any case, the clinician's ability to understand these local idioms is crucial not only for accurate diagnosis, but also for the building of a therapeutic alliance (Kirmayer \& Groleau, 2001). With globalisation, it is likely that these metaphors will change and different idioms of distress will be used. Furthermore, it is possible that an increase in medicalisation of depressive symptoms may be seen.

\section{Depression and guilt}

Feelings of guilt vary in frequency and intensity across cultures. It has been suggested that they are more evident in cultures that both foster a sense of wrongdoing and culpability and encourage individuals to assume responsibility for their actions (Rwegellera, 1981). Murphy et al (1967) supposed that guilt is confined to patients from Judaeo-Christian cultures. Other authors, however, report that patients from different backgrounds, including Muslims and Coptic Christians, Nigerians, Ghanaians and Japanese, all experience guilt in depression (Field, 1960; Kimura, 1965; El-Islam, 1969; Binitie, 1975). Again, whether this change is related to urbanisation remains speculative.

Earlier studies suggested that phenomena of guilt in the Indian subcontinent were 
rare, but more recent research shows that this is not always the case (Bhugra, 1996); in a study of 75 patients with depression in north India, more than half reported feelings of guilt (Bhugra et al, 1997a). There was no difference in the prominence of guilt according to the patient's gender or religious affiliation. Indian families have high expectations of the individual, and this means that the individual may be under pressure to subsume personal needs to benefit the family or the kinship. Again, it is possible that these symptoms are increasing as a result of urbanisation.

The word 'guilt' in Arabic is equivalent to 'sin' and is associated with anti-religious behaviour. Guilt in Arabic culture often is expressed in behaviour, rather than being appreciated as a conscious experience. Hamdi et al (1997) support the view that guilt feelings are less readily elicited in Arabs and may require higher degrees of rapport between patient and clinician; guilt, as well as loss of libido, they argue, has minimal predictive value for the diagnosis of depression, because relevant questions in the traditional Islamic culture cause discomfort and are considered inappropriate. El-Islam, on the other hand, considers guilt a common phenomenon in Muslim groups (El-Islam, 1969; El-Islam et al, 1988). Sulaiman et al (2001b) also identified guilt as a symptom of depression in Dubai. These authors suggest that the inconsistency of findings in different Arab countries could be attributed to the branch of Islam followed (Shia or Sunni).

\section{Suicide}

Ethnicity has been recognised as an important variable in suicide research. Several authors have reported variations across cultures in the lifetime rates of suicide attempts (Sartorius et al, 1983; La Vecchia et al, 1994; Weissman et al, 1996). Interestingly, the rates are relatively favourable in less developed countries, in contrast with the upward trends (particularly for men) in several developed ones.

Early studies from the UK suggested that Asian women had higher rates of attempted suicide than the native population (Merrill \& Owens, 1986; Glover et al, 1989). Examining episodes of self-harm over a 1-year period in an area of London, Bhugra et al (1999a) confirmed that women from the Indian subcontinent had the highest overall rates, especially in the younger age group, and this was attributed to social and cultural stress (Bhugra et al, 1999b). Rates among Black (AfricanCaribbean or African) men and women were lower than expected and in contrast to American samples. Neeleman \& Wessely (1999) tested the 'density hypothesis', which proposes that a better fit between individual and neighbourhood is associated with better health.

Studies from the USA suggest that suicide rates differ between ethnic groups, although the results are inconsistent. Although it was thought that Puerto Ricans have higher rates of suicidal ideation and attempts than Whites or other Latin Americans, when this is examined in relation to depression, men from Puerto Rico and Mexican Americans have lower relative rates than White men (Oquendo et al, 2001). Furthermore, the reported suicide rate for Hispanic Americans is almost half that of non-Hispanic Whites. The emphasis on close relationships and the expectation of adversity may contribute to lower suicide rates in the Hispanic group. In the study by Oquendo et al (2001), Whites, Cuban Americans and Blacks had the highest suicide rates relative to the rates of major depression. Among women, Whites had the highest rates. There is evidence suggesting that the pattern of reported lower suicide rates in Blacks has been changing over the past two decades (Griffith \& Bell, 1989; Stack, 1998).

These findings suggest not only different risk factors for suicide among different cultures, but the presence of as yet undetermined cultural (and even biological) protective factors as well. The identification of these factors should be the core of any suicide preventive strategy. There is an urgent need to study these rates with reference to the impact of urbanisation (which is a consequence of globalisation).

\section{Treatment}

\section{Psychopharmacology}

Ethnic variations in response to psychotropic medication are known to exist as a result of both pharmacokinetic and pharmacodynamic differences. In a comparison of the pharmacokinetic profiles of tricyclic antidepressant drugs, White patients appear to have lower plasma levels and attain peak levels later than Asian patients (Kishimoto \& Hollister, 1984; Rudorfer et al, 1984). Lewis et al (1980), comparing the profile of clomipramine in south Asian, Indian and Pakistani immigrants with that in British Whites, found that all the Asian patients had higher blood levels of drug than the White patients. When the study was repeated with a group of Asians who had changed to a more Western diet, this observed difference disappeared. Since clomipramine is metabolised by CYP3A4, ethnic differences in the pharmacokinetics of this drug may be secondary to the effect of dietary practices. Interactions resulting from the use of traditional medication, different levels of stress, and other environmental and social factors may also affect both the pharmacokinetics and pharmacodynamics of psychotropic medication (Bhugra \& Bhui, 1999). Howson et al (1998) suggest that with globalisation novel therapeutics can be developed by studying indigenous biological resources.

The overwhelming majority of pharmaceutical products used in developing countries are imported from the developed world. Six Western European countries, Japan and the USA are responsible for three-quarters of exports to developing countries (Ballance et al, 1992), and yet pharmacological research into ethnic differences is extremely limited. Possible explanations for such differences are slow hydroxylation (Kilow, 1982), receptor hypersensitivity (Lin et al, 1995) and slow metabolism (Kishimoto \& Hollister, 1984), but research evidence remains inconsistent. There is also evidence that African Americans are more sensitive to the side-effects of antidepressants (Brown et al, 1999), but the underlying mechanism is not clear.

\section{Genetic factors}

Genes that encode enzymes responsible for the metabolism of drugs, as well as genes controlling the function and response of therapeutic targets, may be involved in ethnic differences. Lin (2001), reviewing the relevant studies, reports ethnic differences in the activity of CYP2D6, CYP2C19 and CYP3A4. These enzymes are most commonly involved in psychotropic drug metabolism.

With human migration across national boundaries and the growth of interracial relationships, the genetic components of such differences will also change in time as part of the globalisation process. 


\section{Non-biological factors}

Health systems, public health priorities, local health policy factors - even regional drug policies - play an important part in determining the treatment patients receive. In the WHO Study on Psychological Problems in General Health Care (Sartorius et $a l, 1996)$ it was reported that antidepressants were the favoured form of pharmacotherapy in Seattle and Manchester, whereas in Paris and Rio de Janeiro anxiolytics were prescribed more often for the treatment of depression and anxiety. In India there are more than half a dozen preparations of fluoxetine and its cost is similar to that of tricyclic antidepressants; this, in addition to its having fewer sideeffects and lower drop-out rates, makes it probably more cost-effective in India than in the West (Patel, 2000).

Patients' beliefs also influence patterns of help-seeking. Many cultures evince a preference for a non-medical, self-reliant model of managing depression (Bhugra et $a l, 1997 b$; Pang, 1998). Families, other personal contacts or traditional healers instead of professional help may be sought after symptom onset. The changes in milieu and the need to be seen as modern and progressive that result from globalisation must mean that beliefs about illness and pathways into care will change.

\section{Compliance with treatment}

Studies in general health care suggest that $10-75 \%$ of patients do not comply with treatment, especially in transcultural settings (Kirmayer, 2001). Kinzie et al (1987) reported that $61 \%$ of south-east Asians in the USA receiving antidepressants had no detectable blood level of the drug. Kroll et al (1990) showed that half of refugee south-east Asian patients who claimed to be taking antidepressants had no detectable blood level of the drug and only $16 \%$ had levels in the therapeutic range. Cultural differences in expectations for treatment and divergence in the beliefs between patient and clinician, inadequate communication, the social stigma associated with psychiatric treatment and increased sensitivity to side-effects have been regarded as major reasons for such ethnic differences in treatment adherence (Lin et al, 1995; Bhugra \& Bhui, 1999; Kirmayer, 2001). Educational packages could probably improve compliance, provided they are culturally appropriate (Bhugra \& Bhui, 1999).

\section{CONCLUSIONS}

The experience of depression is recognisable across different cultures, although researchers agree that clinical presentation may vary significantly and that globalisation is likely to influence both idioms of distress and pathways to care.

Somatic symptoms are a prominent feature of depression and it is hopeful that contemporary cultural psychiatry identifies them more as culturally determined 'somatic metaphors' than part of a 'somatisation' process. Is there only one type of depressive illness? In order to clarify this, certain methodological problems in crosscultural research should be overcome. It is, of course, entirely possible that the fact that more depression is being recognised in developing countries reflects altered patterns of diagnosis and symptoms of depression as a result of global factors, knowledge obtained through media and stresses related to urbanisation and industrialisation, which are a consequence of globalisation.

Measuring depression across cultures has always been a source of controversy. Bebbington (1993) characterised transcultural psychiatry as 'a jungle of speculation but a desert of information'. Quantitative research has proved to be of limited value and a more flexible and complex approach needs to be developed. Qualitative research techniques and focus-group methods seem to be more useful in collecting information and identifying needs, especially in minority populations, although these methods have their limitations too. In this era of globalisation the challenge for cultural psychiatry is to identify genuine differences between populations, without being misled by ethnic stereotyping. Individual differences are as great as ethnic ones, and the clinician treats the individual within the larger socio-economic context, not the ethnic group.

\section{REFERENCES}

Abusah, P. (1993) Multi-cultural influences in case management: transcultural psychiatry. Mental Health in Australia, 5, 67-75.

American Psychiatric Association (1994) Diagnostic and Statistical Manual of Mental Disorders (4th edn) (DSM-IV). Washington, DC: APA.

Ballance, R., Pogany, J. \& Forstner, H. (1992) The World's Pharmaceutical Industries: An International Perspective on Innovation, Competition and Policy. United Nations Industrial Development Organization Document, UK. Camberley: Edward Elgar.
Ballenger, J. C., Davidson, J. R. T., Lecrubier, T., et al (200I) Consensus statement on transcultural issues in depression and anxiety from the International Consensus Group on Depression and Anxiety. Journal of Clinical Psychiatry, 62 (suppl. 13), 47-55.

Bauman, Z. (1998) Globalization: The Human Consequences. Cambridge: Polity.

Bebbington, P. (1993) Transcultural aspects of affective disorders. International Review of Psychiatry, 5, 145-156.

Bhatt, A., Tomenson, B. \& Benjamin, S. (1989) Transcultural patterns of somatisation in primary care: a preliminary report. Journal of Psychosomatic Research, 33, 67I-680.

Bhugra, D. (1996) Depression across cultures. Primary Care Psychiatry, 2, 155-165

Bhugra, D. (200I) Services for ethnic minorities: conceptual issues. In Psychiatry in Multicultural Britain (eds D. Bhugra \& R. Cochrane). pp. 330-349. London: Gaskell.

Bhugra, D. \& Ayonrinde, O. (2004) Depression in migrants and ethnic minorities. Advances in Psychiatric Treatment, 10, 13-17.

Bhugra, D. \& Bhui, K. (1999) Ethnic and cultural factors in psychopharmacology. Advances in Psychiatric Treatment, 5, 89-95.

Bhugra, D., Gupta, K. R. \& Wright, B. (1997a) Depression in north India - a comparison of symptoms and life events with other patient groups. International Journal of Psychiatry in Clinical Practice, I, 83-87.

Bhugra, D., Baldwin, D. \& Desai, M. (1997b) Focus groups: implications for primary and cross-cultural psychiatry. Primary Care Psychiatry, 3, 45-50.

Bhugra, D., Desai, M. \& Baldwin, D. (1999a) Attempted suicide in west London, I. Rates across ethnic communities. Psychological Medicine, 29, I125-1130.

Bhugra, D., Baldwin, D., Desai, M., et al (1999b) Attempted suicide in west London, II. Inter-group comparisons. Psychological Medicine, 29, II3I-II39.

Bhui, K. (1999) Common mental disorders among people with origins in or immigrant from India and Pakistan. International Review of Psychiatry, II, 136-144.

Bhui, K. (200I) Epidemiology and social issues. In Psychiatry in Multicultural Britain (eds D. Bhugra \& R. Cochrane), pp 49-74. London: Gaskell.

Bhui, K. \& Bhugra, D. (200I) Transcultural psychiatry: some social and epidemiological research issues. International Journal of Social Psychiatry, 47, I-9.

Bhui, K., Bhugra, D., Goldberg, D., et al (200I) Cultural influences on the prevalence of common mental disorder, general practitioners' assessments and helpseeking among Punjabi and English people visiting their general practitioner. Psychological Medicine, 31, 815-825.

Bibeau, G. (1997) Cultural psychiatry in a creolizing world: questions for a new research agenda. Transcultural Psychiatry, 34, 9-4I.

Binitie, A. (1975) A factor-analytical study of depression across cultures (African and European). British Journal of Psychiatry, I27, 559-563.

Bland, R. C. (1997) Epidemiology of affective disorders: a review. Canadian Journal of Psychiatry, 42, 367-377.

Blue, I., Ducci, M. E., Jaswal, S., et al (1995) The mental health of low income urban women. In Urbanisation and Mental Health in Developing Countries (edsT. Harpham \& I. Blue), pp. 75-102. Aldershot: Avebury.

Borowsky, S. J., Rubenstein, L.V., Meredith, L. S., et al (2000) Who is at risk of non-detection of mental 
health problems in primary care? Journal of General Internal Medicine, 15, 38I-388.

Brewin, C. (1980) Explaining the lower rate of psychiatric treatment among Asian immigrants to the United Kingdom: a preliminary study. Social Psychiatry, I5, 17-19.

Brown, C., Schulberg, H. C., Sacco, D., et al (1999) Effectiveness of treatments for major depression in primary medical care practice: a post hoc analysis of outcomes for African American and white patients. Journal of Affective Disorders, 53, 185-192.

Comino, E. J., Silove, D., Manicavasagar, V., et al (200I) Agreement in symptoms of anxiety and depression between patients and GPs: the influence of ethnicity. Family Practice, 18, 7I-77.

Commander, M. J., Sashi Dharan, S. P., Odell, S. M., et al (1997a) Access to mental health in an inner-city health district. I: Pathways into and within specialist psychiatric services. British Journal of Psychiatry, I70, 312-316.

Commander, M. J., Sashi Dharan, S. P., Odell, S. M., et al (1997b) Access to mental health in an inner city health district. II: Association with demographic factors. British Journal of Psychiatry, 170, 317-320.

Comstock, M. S. \& Helsing, K. J. (1976) Symptoms of depression in two communities. Psychological Medicine, 6, $551-563$.

Desjarlais, R., Eisenberg, L., Good, B., et al (1995) World Mental Health. Problems and Priorities in LowIncome Countries. Oxford: Oxford University Press.

Diala, C. C., Muntaner, C., Walrath, C., et al (200I) Racial/ethnic differences in attitudes toward seeking professional mental health services. American Journal of Public Health, 9I, 805-807.

Ebert, D. \& Martus, P. (1994) Somatisation as a core symptom of melancholic type depression: evidence from a cross-cultural study. Journal of Affective Disorders, 32, 253-256.

Ebigbo, P. (1982) Development of a culture specific (Nigeria) screening scale of somatic complaints. Culture, Medicine and Psychiatry, 6, 29-44.

El-Islam, F. M. (1969) Depression and guilt: study at an Arab psychiatric clinic. Social Psychiatry, 4, 56-58.

El-Islam, F. M., Moussa, M. A., Askar, M., et al (1988) Assessment of depression in Kuwait by principal component analysis. Journal of Affective Disorders, 14, 109-114.

Fabrega, H. (1989) Cultural relativism and psychiatric illness. Journal of Nervous and Mental Disease, I77. $415-425$

Field, M. J. (1960) Search for Security: An Ethnopsychiatric Study of Rural Ghana. London: Faber.

Friedman, J. (1988) Life Space and Economic Space: Essays in Third World Planning. Oxford: Transaction Press.

Giddens, A. (1990) The Consequences of Modernity. Stanford: Stanford University Press.

Gillam, S., Jarman, B., White, P., et al (1980) Ethnic differences in consultation rates in urban general practice. BMJ, 289, 953-957.

\section{Glover, G., Marks, F. \& Nowers, M., (1989)}

Parasuicide in young Asian women. British Journal of Psychiatry, 154, 27I-272.

Goldberg, D. (1999) Cultural aspects of mental disorder in primary care. In Ethnicity: An Agenda for Mental Health (eds D. Bhugra \& V. Bahl), pp. 23-28. London: Gaskell.

Goldberg, D. P. \& Lecrubier, Y. (1995) Form and frequency of mental disorders across centres. In Mental
IIIness in General Health Care: An International Study (eds T. B. Ustun \& N. Sartorius), pp. 323-334. Chichester: John Wiley.

Griffith, E. E. \& Bell, C. (1989) Recent trends in suicide and homicide among blacks. JAMA, 154, 27I-272.

Hamdi, E., Yousreya, A. \& Abou-Saleh, M. T. (1997) Problems in validating endogenous depression in the Arab culture by contemporary diagnostic criteria. journal of Affective Disorders, 44, I3I-|43.

Harpham, T. (1994) Urbanisation and mental health in developing countries. Social Science and Medicine, 39, 233-245

Harpham, T., Lusty, T. \& Vaughan, P. (1988) In the Shadow of the City. Oxford: Oxford University Press.

Harvey, D. (1989) The Condition of Post-modernity Oxford: Blackwell.

Howson, C. P., Fineberg, H. v. \& Bloom, B. R. (1998)

The pursuit of global health: the relevance of engagement for developing countries. Lancet, 35I, 586-590.

Inda, J. \& Rosaldo, R. (2002) Introduction: a world in motion. In The Anthropology of Globalization: A Reader (eds J. X. Inda \& R. Rosaldo), pp. I-34. Oxford: Blackwell.

Jackson-Triche, M. E., Sullivan, G., Wells, K., et al (2000) Depression and health-related quality in ethnic minorities seeking care in general medical settings. Journal of Affective Disorders, 58, 89-97.

Jacob, K. S., Bhugra, D., Lloyd, K. R., et al (1998) Common mental disorders, explanatory models and consultation behaviour among Indian women living in the UK. Journal of the Royal Society of Medicine, 91, 66-7I.

Jenkins, J. H. (1988) Ethnopsychiatric interpretations of schizophrenic illness: the problem of nervios within Mexican-descent families. Culture, Medicine and Psychiatry, 12, 303-331.

Jones, R. J. B. (1995) Globalization and Interdependence in the International Political Economy. London: Pinter.

Katon, W. \& Walker, E. A. (1998) Medically unexplained symptoms in primary care. Journal of Clinical Psychiatry, 59 (suppl. 20), I5-2I.

Kessler, R. C., McGonagle, K. A., Zhao, S., et a (1994) Lifetime and I2-month prevalence of DSM-III-R psychiatric disorders in the United States. Results from the National Comorbidity Survey. Archives of General Psychiatry, 5I, 8-19.

Kilow, W. (1982) Ethnic differences in drug metabolism Clinical Pharmacokinetics, 7I, 373-400.

Kimura, B. (1965) Vergleichende Untersuchungen über depressive Erkrangungen in Japan und in Deutschland. Fortschritte der Neurologie und Psychiatrie, 33, 202-215.

Kinzie, J. D., Leung, P., Boehnlein, J. K., et al (1987) Antidepressant blood levels in Southeast Asians: clinica and cultural implications. Journal of Nervous and Mental Disease, I75, 480-485.

Kirmayer, L. J. (200I) Cultural variations in the clinical presentation of depression and anxiety: implications for diagnosis and treatment. Journal of Clinical Psychiatry, 62 (suppl. 13), 22-28.

Kirmayer, L. J. \& Groleau, D. (200I) Affective disorders in cultural context. Psychiatric Clinics of North America, 24, 465-478.

Kirmayer, L. J. \& Minas, I. H. (2000) The future of cultural psychiatry: an international perspective. Canadian Journal of Psychiatry, 45, 438-446.

Kirmayer, L. J. \& Young, A. (1998) Culture and somatization: clinical, epidemiological and ethnographic perspectives. Psychosomatic Medicine, 60, 420-430.
Kishimoto, A. \& Hollister, L. E. (1984) Nortriptyline kinetics in Japanese and Americans. Journal of Clinical Psychopharmacology, 4, 171-172.

Kleinman, A. (1988) Rethinking Psychiatry. New York: Free Press.

Kleinman, A. (1991) Preface. In Psychosocial Aspects of Depression (eds J. Becker \& A. Kleinman). London: LEA.

Kroll, J., Linde, P., Habenicht, M., et al (1990)

Medication compliance, antidepressant blood levels and side effects in Southeast Asian patients. Journal of Clinical Psychopharmacology, 10, 279-283.

Kunitz, S. J. (2000) Globalization, states, and the health of indigenous peoples. American Journal of Public Health, 90, $153 \mid-1539$.

\section{La Vecchia, C., Lucchini, F. \& Levi, F. (1994)}

Worldwide trends in suicide mortality, 1955-1989. Acta Psychiatrica Scandinavica, 90, 53-64.

Lecrubier, Y. (1998) Is depression under-recognised and undertreated? International Clinical Psychopharmacology, 13 (suppl. 5), 3-6.

Lecrubier, Y. (200I) Prescribing patterns for depression and anxiety worldwide. Journal of Clinical Psychiatry, 62 (suppl. 13), 3I-36.

Lee, K. (2000) The impact of globalization on public health: implications for the UK faculty of public health medicine. Journal of Public Health Medicine, 22. 253-262.

Lee, S. (1998) Estranged bodies, simulated harmony and misplaced cultures: neurasthenia in contemporary Chinese society. Psychosomatic Medicine, 60, 448-457.

Leff, J. P. (1977) International variations in the diagnosis of psychiatric illness. British Journal of Psychiatry, I3I, 329-338.

Leo, R. J., Sherry, C. \& Jones, A.W. (1998) Referral patterns and recognition of depression among AfricanAmerican and Caucasian patients. General Hospital Psychiatry, 20, 175-182

Lepine, J.-P. (200I) Epidemiology, burden and disability in depression and anxiety. Journal of Clinical Psychiatry, 62 (suppl. 13), 4-10.

Lewis, P., Rack, P. H., Vaddadi, K. S., et al (1980)

Ethnic differences in drug response. Postgraduate Medical Journal, 56 (suppl. I), 46-49.

Lin, K. M. (200I) Biological differences in depression and anxiety across races and ethnic groups. Journal of Clinical Psychiatry, 62 (suppl. 13), 13-19.

Lin, K. M., Poland, R. \& Anderson, D. (1995)

Psychopharmacology, ethnicity and culture. Transcultural Psychiatric Research Review, 32, 3-40.

Lloyd, K. (1998) Ethnicity, social inequality and mental illness. BMJ, 316, 1763.

Lloyd, K., Jacob, K. \& Patel,V. (1996) The Development of the Short Explanatory Model Interview and lts Use Among Primary Care Attenders. London: Institute of Psychiatry.

Mahadevia, D. (2002) Communal space over life space: saga of increasing vulnerability in Ahmedabad. Economic and Political Weekly, 30 November.

Manson, S. M. (1995) Culture and major depression. Current challenges in the diagnosis of mood disorders. Psychiatric Clinics of North America, 18, 487-50I.

Marsella, A. (1995) Urbanisation, mental health and psychosocial well-being. In Urbanisation and Mental Health in Developing Countries (edsT. Harpham \& I. Blue), pp. 17-40. Aldershot: Avebury.

Maser, J. D., Kaelber, C. \& Weise, R. E. (1991) International use and attitudes toward DSM-III and 
DSM-III-R: growing consensus in psychiatric classification. Journal of Abnormal Psychology, 100 27I-279.

Meltzer, H., Gill, B., Pettigrew, M., et al (1995) The Prevalence of Psychiatric Morbidity Among Adults Living in Private Households. London: Stationery Office.

Merrill, J. \& Owens, J. (1986) Ethnic differences in selfpoisoning: a comparison of Asian and White groups. British journal of Psychiatry, 148, 708-712.

\section{Murphy, H. S. M., Wittkower, E. D. \& Chance, N.}

(1967) Cross-cultural inquiry into the symptomatology

of depression: a preliminary report. International journal of Psychiatry, 3, 6-15.

Murray, C. J. L. \& Lopez, A. D. (1997) Alternative projections of mortality and disability by cause 1990 2020: global burden of disease study. Lancet, 349, 1498-1504.

Nazroo, J. (1997) Ethnicity and Mental Health. London Policy Studies Institute.

Neeleman, J. \& Wessely, S. (1999) Ethnic minority suicide: a small area geographical study in south London. Psychological Medicine, 29, 429-436.

Neff, J. A. \& Husaini, B. A. (1980) Race,

socioeconomic status and psychiatric impairment: a research note. Journal of Community Psychology, 8, 16-19.

Oquendo, M. A., Ellis, S. P., Greenwald, S., et al (200I) Ethnic and sex differences in suicide rates relative to major depression in the United States. American Journal of Psychiatry, 158, 1652-1658.

Pang, K. Y. C. (1998) Symptoms of depression in elderly Korean immigrants: narration and the healing process. Culture, Medicine and Psychiatry, 22, 93-122.

Park, R., Burgess, E. \& McKenzie, R. (1925) The City Chicago, IL: University of Chicago Press.

Parker, G., Gladstone, G. L. \& Chee, K.T. (200I) Depression in the planet's largest ethnic group: the Chinese. American Journal of Psychiatry, 158, 857-864.

Patel, V. (2000) The need for treatment evidence for common mental disorders in developing countries. Psychological Medicine, 30, 743-746.

Persaud, R. B. \& Lusane, C. (2000) The new economy globalization and the impact on African Americans. Race and Class, 42, 21-34.

Rait, G., Burns, A., Baldwin, R., et al (1999) Screening for depression in African-Caribbean elders. Family Practice, 16, 591-595.

Roberts, R. E., Stevenson, J. M. \& Breslow, L. (198I) Symptoms of depression among Blacks and Whites in an urban community. Journal of Nervous and Mental Disease, 169, 774-779.

Rudorfer, E., Lam, E., Chang, W., et al (1984) Desipramine pharmacokinetics in Chinese and Caucasian volunteers. British Journal of Clinical Pharmacology, 17, 433-440.

Rwegellera, G. G. C. (1981) Cultural aspects of depressive illness. Psychopathologie Africaine, 17, 4I-63.

Sartorius, N., Davidson, H., Ernberg, G., et al (1983) Depressive Disorders in Different Cultures. Geneva: WHO.

Sartorius, N., Üstün, T. B., Lecrubier, Y., et al (1996) Depression comorbid with anxiety: results from the WHO Study on Psychological Disorders in Primary Health Care. British Journal of Psychiatry, 168 (suppl. 30), $38-43$.

\section{CLINICAL IMPLICATIONS}

- Clinicians need to be aware of the impact of globalisation in the context of changing language, idioms of distress, explanatory models and help-seeking.

- Rates of depression are likely to increase as a result of globalisation and urbanisation.

- These two phenomena will also cause changes in support networks and increase alienation.

\section{LIMITATIONS}

- No reliable measure is available to ascertain the impact of globalisation.

- Cultures may not respond to globalisation by becoming homogeneous, but may become more rigid and inflexible.

- The impact of globalisation needs to be studied at community and individual levels.

DINESH BHUGRA, MPhil, FRCPsych, PhD, ANASTASIA MASTROGIANNI, MD, Institute of Psychiatry, London, UK

Correspondence: Professor Dinesh Bhugra, PO Box 25, Institute of Psychiatry, De Crespigny Park, London SE5 8AF, UK

(First received 29 April 2002, final version 24 June 2003, accepted I July 2003)

Shaw, C. M., Creed, F., Tomenson, B., et al (1999) Prevalence of anxiety and depressive illness and help seeking behaviour in African Caribbeans and White Europeans: two phase general population survey. BMJ 318, 302-306.

Simon, G. E., Von Korff, M., Piccinelli, M., et al (1999) An international study of the relation between somatic symptoms and depression. New England Journal of Medicine, 34I, 1329-1335.

Somervell, P. D., Leaf, P. J., Weissman, M. M., et al (1989) The prevalence of major depression in black and white adults in five United States communities. American Journal of Epidemiology, I30, 725-735.

Stack, S. (1998) Culture and suicide among African Americans. Transcultural Psychiatry, 35, 253-269.

\section{Sulaiman, S., Bhugra, D. \& De Silva, P. (200la)}

Perception of depression in a community sample in Dubai. Transcultural Psychiatry, 38, 201-218.

Sulaiman, S., Bhugra, D. \& De Silva, P. (200Ib) The development of a culturally sensitive symptom checklist for depression in Dubai. Transcultural Psychiatry, 38, 219-229.

Thakker, J. \& Ward, T. (1998) Culture and classification. The cross-cultural application of the DSMIV. Clinical Psychology Review, 18, 50I-529.

Tomlinson, J. (1997) International globalization and cultural imperialism. In Media and Cultural Regulation (ed K. Thompson), pp. I17-162. London: Sage.
Weiss, M. G., Doonagaji, D. R., Siddhartha, S., et al (1992) The Explanatory Model Interview Catalogue (EMIC). Contribution to cross-cultural research methods from a study of leprosy and mental health. British Journal of Psychiatry, 160, 819-830.

Weiss, M. G., Raguram, R. \& Channabasavanna, S. M. (1995) Cultural dimensions of psychiatric diagnosis. A comparison of DSM-III-R and illness explanatory models in south India. British Journal of Psychiatry, 166 353-359.

Weissman, M. M., Bland, R. C., Canino, G. J., et al (1996) Cross-national epidemiology of major depression and bipolar disorder. JAMA, 276, 293-299.

World Bank (1993) World Development Report 1993 Investing In Health. New York: Oxford University Press.

World Health Organization (1992) International Statistical Classification of Diseases and Related Health Problems (ICD-10). Geneva: WHO.

World Health Organization (2002) World Report on Violence and Health. Geneva: WHO.

Zhang, W. X., Shen, Y. C. \& Li, S. R. (1998) Epidemiological investigation on mental disorders in 7 areas of China. Clinical Journal of Psychiatry, 31, 69-7I. 